\title{
The impact of folate intake on the risk of head and neck cancer in the prostate, lung, colorectal, and ovarian cancer screening trial (PLCO) cohort
}

\begin{abstract}
Daisuke Kawakita*1,2,3,4, Yuan-Chin Amy Lee ${ }^{1,2}$, Lisa H Gren ${ }^{1,2}$, Saundra S Buys ${ }^{2,5}$, Carlo La Vecchia ${ }^{6}$ and Mia Hashibe ${ }^{1,2}$

${ }^{1}$ Division of Public Health, Department of Family and Preventive Medicine, University of Utah School of Medicine, Salt Lake City, UT 84108, USA; ${ }^{2}$ Huntsman Cancer Institute, University of Utah School of Medicine, Salt Lake City, UT 84108, USA; ${ }^{3}$ Department of Otorhinolaryngology, Head and Neck Surgery, Nagoya City University Graduate School of Medical Sciences, Nagoya 467-8602, Japan; ${ }^{4}$ Division of Molecular and Clinical Epidemiology, Aichi Cancer Center Research Institute, Nagoya 464-8681, Japan; ${ }^{5}$ Department of Internal Medicine, University of Utah School of Medicine, Salt Lake City, UT 84108, USA and ${ }^{6}$ Department of Clinical Sciences and Community Health, Università degli Studi di Milano, Milan 520133, Italy
\end{abstract}

Background: Although low levels of folate leads to disturbances in DNA replication, DNA methylation and DNA repair, the association between dietary folate intake and head and neck cancer (HNC) risk remains unclear.

Methods: We evaluated the association between folate intake and HNC risk using prospective cohort data from the Prostate, Lung, Colorectal, and Ovarian (PLCO) cancer screening trial. This study included 101700 participants and 186 cases with confirmed incident HNC. The median follow-up was 12.5 years. We estimated hazard ratios (HRs) and the corresponding 95\% confidence intervals (Cls) using Cox proportional hazard model including age, sex, body mass index, education, race, tobacco smoking, alcohol drinking and total fruit and vegetable intake.

Results: Higher intake of food folate and fortified folic acid in foods was associated with a decreasing HNC risk in a doseresponse manner. The HRs of highest vs the lowest quartile of intake were 0.35 (95\% Cl: $0.18-0.67)$ for food folate, and 0.49 (95\% Cl: 0.30-0.82) for fortified folic acid. Intakes of total folate, natural folate and supplemental folic acid were not associated with the risk of HNC and its subsites. We did not detect any interaction between smoking, drinking and food folate intake on HNC risk.

Conclusions: These findings provide evidence of the protective role of dietary folate intake on HNC risk.

In the United States, over 60000 new head and neck cancer (HNC) cases was diagnosed, with over 16000 patients dying from $\mathrm{HNC}$ in 2016, and this is the sixth most common cancer among men (Siegel et al, 2016). Tobacco smoking, alcohol drinking and human papilloma virus (HPV) infection for oropharyngeal cancer are established risk factors (Hashibe et al, 2009; Lubin et al, 2009;
Marur et al, 2010). However, the role of other environmental factors, including dietary factors, remains unclear.

Fruit and non-starchy vegetables, which are rich in minerals, antioxidants, and vitamins including folate, may decrease HNC risk (Pavia et al, 2006; Freedman et al, 2008; Lucenteforte et al, 2009). Folate is a water-soluble vitamin of the B complex group

*Correspondence: Dr D Kawakita; E-mail: dk200811@gmail.com

Received 12 May 2017; revised 17 August 2017; accepted 9 October 2017; published online 21 November 2017

(C) 2018 Cancer Research UK. All rights reserved 0007-0920/18 
and plays a definite role in one-carbon metabolism, which facilitates de novo deoxynucleoside triphosphate synthesis and provides methyl groups required for intracellular methylation reactions (Lamprecht and Lipkin, 2003). Since folate insufficiency leads to disturbances in DNA replication, DNA methylation and DNA repair (Duthie, 1999; Kim, 1999; Choi and Mason, 2002), deficiency of folate intake may increase the risk of HNC. This issue has been evaluated by several epidemiological studies (McLaughlin et al, 1988; De Stefani et al, 1999; Negri et al, 2000; Weinstein et al, 2002; Bidoli et al, 2003; Pelucchi et al, 2003; Suzuki et al, 2007; Shanmugham et al, 2010; Aune et al, 2011; Tavani et al, 2012; Galeone et al, 2015), including one large-scale pooled-analysis (Galeone et al, 2015). Most studies reported that higher folate intake was associated with a decreased HNC risk (Negri et al, 2000; Weinstein et al, 2002; Bidoli et al, 2003; Pelucchi et al, 2003; Suzuki et al, 2007; Shanmugham et al, 2010; Aune et al, 2011; Tavani et al, 2012; Galeone et al, 2015) except for two studies (McLaughlin et al, 1988; De Stefani et al, 1999). Most investigations were case-control studies except for the Nurse's Health Study (Shanmugham et al, 2010), which however considered only the alcohol-folate interaction. Therefore, further evidence and quantification from cohort studies would aid the understanding of the relationship between folate and HNC risk.

In this study, we evaluated the association between folate intake and the risk of HNC using observational prospective data from the Prostate, Lung, Colorectal, and Ovarian (PLCO) cancer screening trial (Prorok et al, 2000).

\section{MATERIALS AND METHODS}

Study design and subjects. The PLCO cancer screening trial is a large-scale clinical trial designed to determine whether selected screening tests reduce deaths from prostate, lung, colorectal, and ovarian cancer (Prorok et al, 2000). The trial started in 1992 and ended enrolment in 2001. Approximately 155000 participants between the ages of 55 and 74 were enrolled at 10 centres across the United States (Alabama, Michigan, Colorado, Hawaii, Wisconsin, Minnesota, Pennsylvania, Utah, Missouri, and Washington DC). Participants were individually randomised to the control arm or intervention arm in equal proportions. Participants assigned to the control arm received usual care, whereas participants assigned to the intervention arm were invited to receive screening exams for prostate, lung, colorectal, and ovarian cancers. Screening of participants ended in late 2006. Follow-up continues for up to 10 more years to determine the benefits or harms of screening tests. Written informed consent was obtained from all study participants. Ethical approval for human subject's research was obtained at each of the centres.

Assessment of lifestyle factors and head and neck cancer confirmation. Subjects randomised to either study arm (control or intervention) were eligible if they had completed the baseline questionnaire and the diet history questionnaire, which was administered to participants in both arms between 1998 and 2005 (Subar et al, 2000). A study update was mailed yearly to participants to ascertain and confirm cancer diagnoses. Participants were asked if they were diagnosed with cancer, which kind of cancer, date of diagnosis, hospital or clinic of diagnosis, and physician contact information. For every cancer reported, medical record abstraction included the cancer diagnosis date and the International Classification of Disease for Oncology, second version (ICD-O-2) code. Vital status was obtained by the administration of the Annual Study Update questionnaire, reports from relatives, friends, or physicians, and National Death Index plus searches. The study centres attempted to obtain a death certificate for each death. If participants were diagnosed with cancer after study entry, which ranged from 1992 to 2001, and before completion of the dietary questionnaire, they were not eligible. HNC cases were diagnosed from enrolment completion to December 2009, the last available follow-up. Only malignant primary HNC cases were considered in the present analysis. Tumours were assigned to one of the five categories as follows: (1) oral cavity: ICD-O-2 codes C00.3 to C00.9, C02.0 to C02.3, C03.0, C03.1, C03.9, C04.0, C04.1, C04.8, C04.9, C05.0, C06.0 to C06.2, C06.8, and C06.9; (2) oropharynx: ICD-O-2 codes C01.9, C02.4, C05.1, C05.2, C09.0, C09.1, C09.8, C09.9, C10.0, C10.2-C10.4, C10.8, and C10.9; (3) hypopharynx: ICD-O-2 codes C12.9, C13.0 to $\mathrm{C} 13.2, \mathrm{C} 13.8$, and $\mathrm{C} 13.9$; (4) oral cavity or pharynx not otherwise specified (NOS): ICD-O-2 codes C02.8, C02.9, C05.8, C05.9, C14.0, C14.2, and C14.8; and (5) larynx: ICD-O-2codes $\mathrm{C} 10.1, \mathrm{C} 32.0$ to $\mathrm{C} 32.3$ and $\mathrm{C} 32.8$ to C32.9. Of the 154897 participants recruited into the PLCO study, 111488 participants completed both the baseline questionnaire and the diet history questionnaire. Of the 111488 participants with valid questionnaires, participants were excluded because: (1) they had cancer before entry into the PLCO study $(n=9697)$; (2) they did not have follow-up time $(n=91)$. Thus, this study included 101700 participants, and 186 cases with confirmed incident HNC. For $\mathrm{HNC}$ cases, the numbers for control $v s$ intervention group were: 93 vs 93.

The baseline questionnaire included information on age, sex, race, education, tobacco smoking, alcohol drinking, family history of cancer, medical history, weight, height and other selected lifestyle factors. Dietary data were collected using a selfadministered food-frequency questionnaire, the Diet History Questionnaire, version 1.0 (National Cancer Institute, 2017), which was distributed to the control and intervention arms of the trial between 1998 and 2005 (Subar et al, 2000). The diet history questionnaire included portion size and frequency of consumption of 124 food item and supplement use during the past year (National Cancer Institute, 2017). Folate intake was estimated in accordance with the following five sources (Oaks et al, 2010): (1) natural folate (polyglutamates found naturally in food), (2) fortified folic acid (folic acid added to food), (3) food folate (a combination of natural folate and fortified folic acid), (4) supplemental folic acid (folic acid from vitamin supplements), and (5) total folate intake (a combination of food folate and supplemental folic acid). Food folate content was based on prefolic acid fortification (1998) database information from the 19941996 Continuing Survey of Food Intake by Individuals (Subar et al, 1995). The post-folic acid grain fortification database information from the Nutrition Data System for Research (NDS-R) was used to estimate folic acid from fortified food. The NDS-R combines nutrition information from the US Department of Agriculture Nutrient Database for Standard Reference, food manufacturers, scientific literature, and other published food tables (University of Minnesota Nutrition Co-ordinating Center, NDSR descriptive overview). Supplemental folic acid use and dose were derived from recent use (current or 2 year ago) of four multivitamins (Oaks et al, 2010): One-a-Day (100\% of the Recommended Dietary Allowance; Bayer Corp, Pittsburgh, PA, USA), a therapeutic or high-dose type ( $>100 \%$ of the Recommended Dietary Allowance; e.g., Theragran; Bristol-Myers Squibb, New York, NY, USA), Stresstabs (Bcomplex + vitamin C; Inverness Medical Inc, Waltham, MA, USA), and B-complex. The B-complex multivitamin was assigned a 200-mcg folic acid dose, whereas the other multivitamins were assigned a 400-mcg folic acid dose.

Statistical analysis. Follow-up time was calculated from the date of entry until the occurrence of one of the following events: diagnosis of HNC, death, or the end of follow-up. We estimated hazard ratios (HRs) and the corresponding 95\% confidence intervals (CIs) of HNC and its subsites for quartile categories of 
folate intake using the Cox proportional hazards model. Models included adjustment for age (categorical), sex, body mass index (BMI) at interview $\left(\leqslant 24.9 \mathrm{~kg} \mathrm{~m}^{-2} v s \geqslant 25 \mathrm{~kg} \mathrm{~m}^{-2}\right)$, education ( $\leqslant$ high school $v s \geqslant$ some college), race (White, non-Hispanic $v s$ Other), pipe and cigar smoking status (never $v s$ former $v s$ current), pack-year cigarette smoking (never $v s<20 \quad v s \geqslant 20$ ), alcohol drinking intensity (never $v s<4.1 \mathrm{~g}$ per day $v s \geqslant 4.1 \mathrm{~g}$ per day), non-alcohol total energy (continuous), and total fruit and vegetable intake (continuous). To test interactions, we performed likelihoodratio tests, which compared models with and without the interaction term.

All statistical analyses were performed using the software STATA version.13 (Stata Corp, College Station, TX, USA). All tests were two-sided.

\section{RESULTS}

The median follow-up was 12.5 years. Table 1 shows the characteristics of the PLCO cohort and the HNC cases. Higher proportions of male, smokers, and drinkers were found in the HNC cases. Other characteristics showed no appreciable difference between the cohort and the HNC cases. The HNC cases consisted of 81 cases of oral cavity, 18 of oropharynx, 10 of hypopharynx, 1 of NOS, and 76 of larynx.

Table 2 gives the multivariate HRs, and the corresponding 95\% $\mathrm{CI}$ for the various sources of folate intake on the risk of HNC and its subsites. Higher intake of food folate and fortified folic acid was associated with a decreased HNC risk in a dose-response manner. The HRs of highest $v s$ the lowest quartile of intake were 0.35 (95\% CI: $0.18-0.67$ ) for food folate, and 0.49 (95\% CI: $0.30-0.82$ ) for fortified folic acid. Although these trends were consistent in laryngeal cancer cases, the impact of food folate or fortified folic acid were weaker than that for oral cavity and pharyngeal cancer cases, especially for fortified folic acid. Intakes of total folate, natural folate, and supplemental folic acid were not observed to be associated with the risk of HNC and its subsites, though all the HRs were below unity.

We also evaluated interactions of cigarette smoking and alcohol drinking with food folate intake on HNC risk (Figures 1 and 2). We found no significant deviation from the multiplicative model between smoking, drinking, and food folate intake on HNC risk (Figure 1: $p_{\text {interaction }}$ for smoking $=0.471$; Figure $2: p_{\text {interaction }}$ for drinking $=0.395$ ). In a multivariate analysis, the HR of high tobacco/low food folate intake $v s$ no tobacco/high food folate intake was 22.09, and high alcohol/low food folate intake vs no alcohol/high food folate intake was 3.57. Additionally, we performed stratified analyses between selected confounders and food folate intake on HNC risk (Figure 3). Food folate intake did not show remarkable heterogeneity by potential confounders, including age, sex, BMI and education, on HNC risk.

\section{DISCUSSION}

In this prospective cohort study, we found a favourable role of food folate and fortified folic acid intake in HNC development. This association was consistent across subsites of HNC, especially for laryngeal cancer cases. The favourable role of folate intake showed no deviation from a multiplicative model with smoking and drinking, and was consistent across strata of known confounders.

To date, nine case-control studies (McLaughlin et al, 1988; De Stefani et al, 1999; Negri et al, 2000; Weinstein et al, 2002; Bidoli et al, 2003; Pelucchi et al, 2003; Suzuki et al, 2007; Aune et al, 2011; Tavani et al, 2012) and one pooled analysis of case-control studies (Galeone et al, 2015) have evaluated the association between folate intake and the risk of HNC or its subsites. Only one study from the USA evaluated the impact of folate intake on the risk of oral cavity and pharyngeal cancer, including 871 cases, and reported no association (McLaughlin et al, 1988). An Uruguayan study also reported no association between folate intake and upper aerodigestive tract (UADT) cancer risk (De Stefani et al, 1999). All other studies reported a favourable effect of folate intake on the risk of $\mathrm{HNC}$ or its subsites. In the study for Puerto Rico (Weinstein et al, 2002), including 341 oral cavity and pharyngeal cases, a favourable role of folate from fruit was observed, but no associations were observed in other sources. Additionally, a more recent Uruguayan study (Aune et al, 2011), including 283 oral cavity and pharyngeal and 281 laryngeal cases, found an interaction of folate intake with smoking status on UADT cancer risk. Smoking induces deactivation of folate coenzymes and vitamin B12 and results in folate deficiency (Heimburger, 1992). These folate deficiency levels were also observed in buccal mucosa among smokers (Piyathilake et al, 1992). In addition, an Italian multi-centre study (Tavani et al, 2012), including 1467 oral cavity and pharyngeal and 851 laryngeal cases, reported a decreased HNC risk associated with folate intake. The OR for the highest $v s$ the lowest of intake was 0.37 for oral cavity and pharynx, and 0.55 for larynx, with dose-response trends. In addition, the International Head and Neck Cancer Epidemiology consortium study, a largescale pooled analysis including 5959 oral cavity and pharyngeal cases, observed that higher folate intake was associated with a decreased risk of oral cavity and pharyngeal cancer (OR: 0.65, 95\%CI: $0.43-0.99$ for the highest $v s$ the lowest of quintile). This association was apparently stronger among hospital-based study than population-based study (Galeone et al, 2015). Additionally, six studies have investigated serum or plasma folate levels to compare between HNC cases and controls (Almadori et al, 2002; Raval et al, 2002; Almadori et al, 2005; Eleftheriadou et al, 2006; Gorgulu et al, 2010; Fanidi et al, 2015). They reported on a significant decreased serum or plasma folate level among HNC cases relative to controls. The European Prospective Investigation into Cancer and Nutrition (EPIC) study reported that higher levels of folate was associated with a decreased HNC risk in a doseresponse manner (OR: 0.63, 95\%CI: 0.35-1.16 for the highest $v s$ the lowest of quantile) (Fanidi et al, 2015). However, this result was attenuated when cases were compared with additional unmatched controls.

Mechanisms of folate intake on HNC risk have been previously proposed. Folate deficiency contributes to the alteration of the normal methylation process and imbalance in the steady-state levels of DNA precursors, inducing aberrant DNA synthesis, stability and repair, and chromosomal changes (Lamprecht and Lipkin, 2003; Ulrich and Grady, 2010). Global and regional hypomethylation and hypermethylation within the CpG islands of specific gene promoters have been identified in HNCs (Hasegawa et al, 2002; Smith et al, 2007). In addition, this may lead to protooncogene activation and chromosomal instability (Smith et al, 2007). Folate-rich foods tend to have a high content of antioxidants, and consequently higher folate intake may be an indicator of a diet rich in fruit, vegetable, and a better general lifestyle pattern (Bosetti et al, 2009). However, we carefully adjusted by total fruit and vegetable intake in a multivariate analysis. In addition, we included other micronutrients, including vitamin B6, vitamin B12, vitamin $\mathrm{C}$, vitamin $\mathrm{E}$, and carotenoids, in multivariate analysis, and a decreased $\mathrm{HR}$ of food folate intake was consistent after adjustment by these factors.

Alcohol drinking induces to modification of folate level (Bailey, 1990). Alcohol drinking leads to reduced folate absorption, increased folate excretion, and inhibited methionine synthase in one-carbon metabolism (Barak et al, 1987; Mason and Choi, 2005). In this study, we detected no effect modification and interaction between alcohol and folate intake on HNC risk. We found two 
Table 1. Characteristics of the PLCO cohort and the head and neck cancer cases

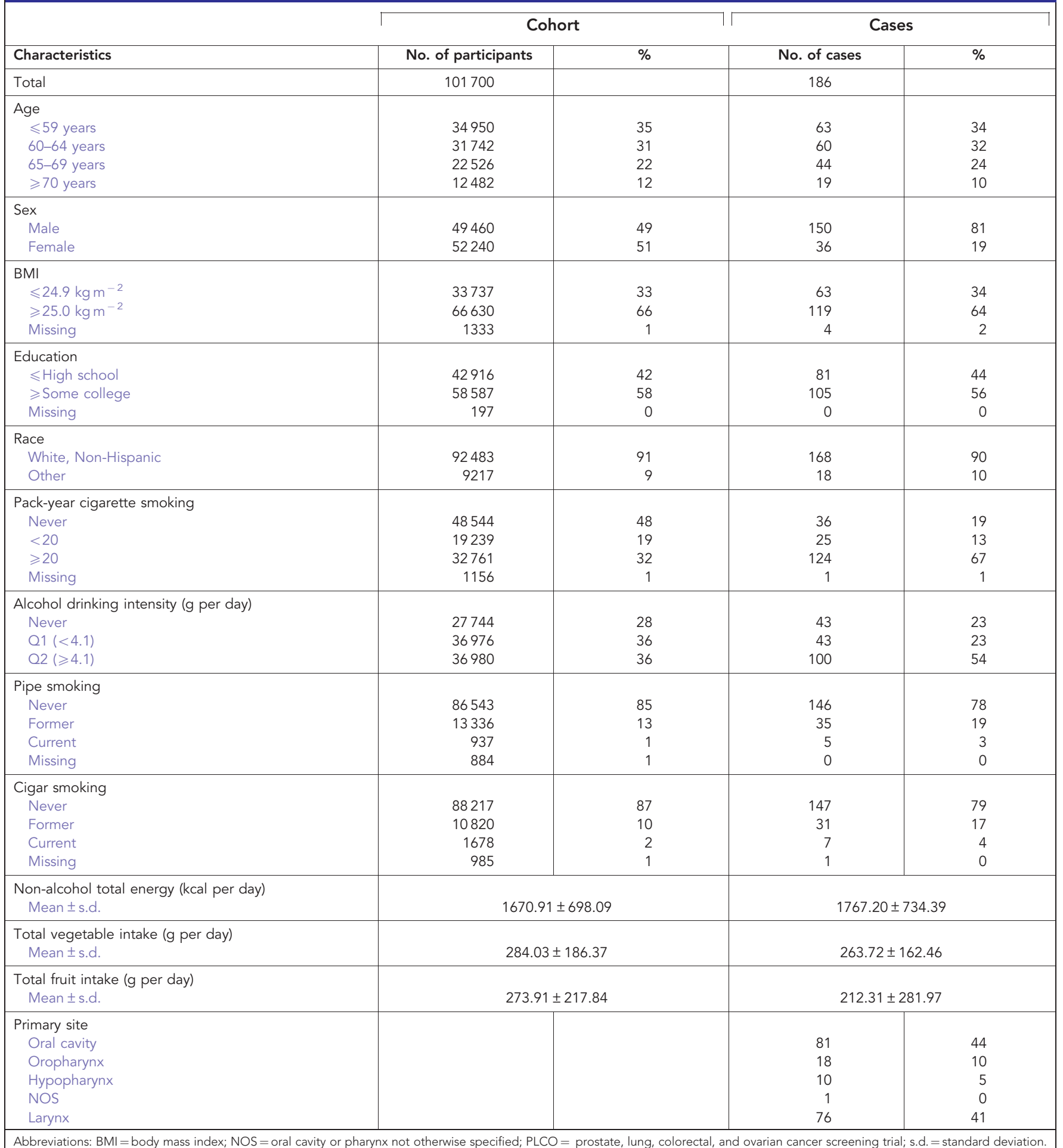

studies which evaluated the interaction between alcohol drinking and folate intake on HNC risk (Shanmugham et al, 2010; Matsuo et al, 2012). The Nurse's Health Study, a prospective cohort of 87621 women and 147 incident oral cancer cases, observed an interaction between alcohol and folate intake $(P$-value $=0.02)$. The relative risk of highest alcohol drinking and low folate intake vs never drinking and high folate intake was 3.36 (95\% CI: 1.57-7.20). Since our highest tertile of alcohol drinking was relatively low, we might explain this inconsistency in this study.

We found no association with supplemental folic acid on HNC risk. A recent meta-analysis, including 13 randomised trials of folic acid supplementation and almost 50000 individual data, reported that folic acid supplementation does not substantially increase incidence of site-specific cancer during the first 5 years of supplementation (Vollset et al, 2013). However, dietary fortification involves doses of folic acid that are an order of magnitude lower than the doses studied in these trials. In addition, our data on supplemental folic acid were only derived from recent use (current or 2 year ago). But, our findings are also consistent with a previous report on pancreatic cancer in PLCO study (Oaks et al, 2010).

Our study has several strengths. With the prospective design, the questionnaire data were collected before cancer diagnosis. 
Table 2. Dietary folate intake and the risk of head and neck cancer or subsites in the PLCO cohort

\begin{tabular}{|c|c|c|c|c|c|c|c|c|c|c|c|c|c|}
\hline & & & Head & and neck & & Ora & l cavit & ty and Pha & rynx & & & rynx & \\
\hline Nutrients & Cohort & Cases & $\mathrm{HR}^{\mathrm{a}}$ & $95 \% \mathrm{Cl}$ & $P$-value & Cases & $\mathrm{HR}^{\mathrm{a}}$ & $95 \% \mathrm{Cl}$ & $P$-value & Cases & $\mathrm{HR}^{\mathrm{a}}$ & $95 \% \mathrm{Cl}$ & $P$-value \\
\hline Total folate ( $\mu \mathrm{g}$ per da) & & & & & & & & & & & & & \\
\hline $\mathrm{Q} 2(\geqslant 375.91$ to $<611.80)$ & 25426 & 52 & 0.91 & $0.62-1.35$ & 0.643 & 24 & 0.65 & $0.38-1.12$ & 0.119 & 27 & 1.33 & $0.75-2.38$ & 0.329 \\
\hline $\mathrm{Q} 3(\geqslant 611.80$ to $<780.26)$ & 25422 & 36 & 0.71 & $0.47-1.09$ & 0.121 & 25 & 0.74 & $0.44-1.26$ & 0.268 & 11 & 0.64 & $0.31-1.33$ & 0.234 \\
\hline $\mathrm{Q} 4(\geqslant 780.26)$ & 25428 & 39 & 0.72 & $0.45-1.16$ & 0.183 & 25 & 0.64 & $0.35-1.18$ & 0.157 & 14 & 0.85 & $0.40-1.82$ & 0.676 \\
\hline$P_{\text {trend }}$ & & & & 0.090 & & & & 0.220 & & & & 0.261 & \\
\hline Q1 $(<261.36)$ & 25425 & 61 & 1.00 & - & - & 30 & 1.00 & - & - & 30 & 1.00 & - & - \\
\hline $\mathrm{Q} 2(\geqslant 261.36$ to $<350.41)$ & 25422 & 33 & 0.47 & $0.30-0.73$ & 0.001 & 22 & 0.65 & $0.36-1.16$ & 0.143 & 11 & 0.30 & $0.15-0.63$ & 0.001 \\
\hline $\mathrm{Q} 3(\geqslant 350.41$ to $<461.90)$ & 25427 & 54 & 0.64 & $0.41-1.01$ & 0.056 & 32 & 0.83 & $0.45-1.50$ & 0.532 & 22 & 0.50 & $0.25-1.00$ & 0.051 \\
\hline $\mathrm{Q} 4(\geqslant 461.90)$ & 25426 & 38 & 0.35 & $0.18-0.67$ & 0.002 & 25 & 0.52 & $0.23-1.22$ & 0.132 & 13 & 0.21 & $0.07-0.62$ & 0.005 \\
\hline$p_{\text {trend }}$ & & & & 0.009 & & & & 0.265 & & & & 0.013 & \\
\hline Natural folate ( $\mu \mathrm{g}$ per & ay) & & & & & & & & & & & & \\
\hline Fortified folic acid ( $\mu \mathrm{g}$ & er day) & & & & & & & & & & & & \\
\hline $\mathrm{Q} 1(<71.20)$ & 25421 & 49 & 1.00 & - & - & 25 & 1.00 & - & - & 23 & 1.00 & - & - \\
\hline $\mathrm{Q} 2(\geqslant 71.20$ to $<109.89)$ & 25428 & 47 & 0.91 & $0.61-1.38$ & 0.665 & 25 & 0.96 & $0.54-1.68$ & 0.877 & 22 & 0.90 & $0.50-1.65$ & 0.744 \\
\hline $\mathrm{Q} 3(\geqslant 109.89$ to $<163.35)$ & 25421 & 55 & 0.95 & $0.63-1.44$ & 0.810 & 35 & 1.22 & $0.70-2.11$ & 0.482 & 20 & 0.72 & $0.38-1.39$ & 0.330 \\
\hline $\mathrm{Q} 4(\geqslant 163.35)$ & 25430 & 35 & 0.49 & $0.30-0.82$ & 0.006 & 24 & 0.70 & $0.37-1.35$ & 0.290 & 11 & 0.32 & $0.14-0.73$ & 0.007 \\
\hline ptrend & & & & 0.014 & & & & 0.473 & & & & 0.008 & \\
\hline Supplemental folic acio & ( $\mu \mathrm{g}$ per $c$ & day) & & & & & & & & & & & \\
\hline $\mathrm{Q} 1(=0)$ & 38080 & 88 & 1.00 & - & - & 53 & 1.00 & - & - & 35 & 1.00 & - & - \\
\hline $\mathrm{Q} 2(\geqslant 0$ to $<400)$ & 15767 & 26 & 0.86 & $0.56-1.34$ & 0.513 & 11 & 0.63 & $0.33-1.18$ & 0.148 & 14 & 1.26 & $0.68-2.35$ & 0.468 \\
\hline $\mathrm{Q} 3(\geqslant 400)$ & 47853 & 72 & 0.81 & $0.59-1.11$ & 0.196 & 44 & 0.75 & $0.50-1.12$ & 0.155 & 27 & 0.89 & $0.53-1.47$ & 0.644 \\
\hline$p_{\text {trend }}$ & & & & 0.194 & & & & 0.153 & & & & 0.669 & \\
\hline
\end{tabular}

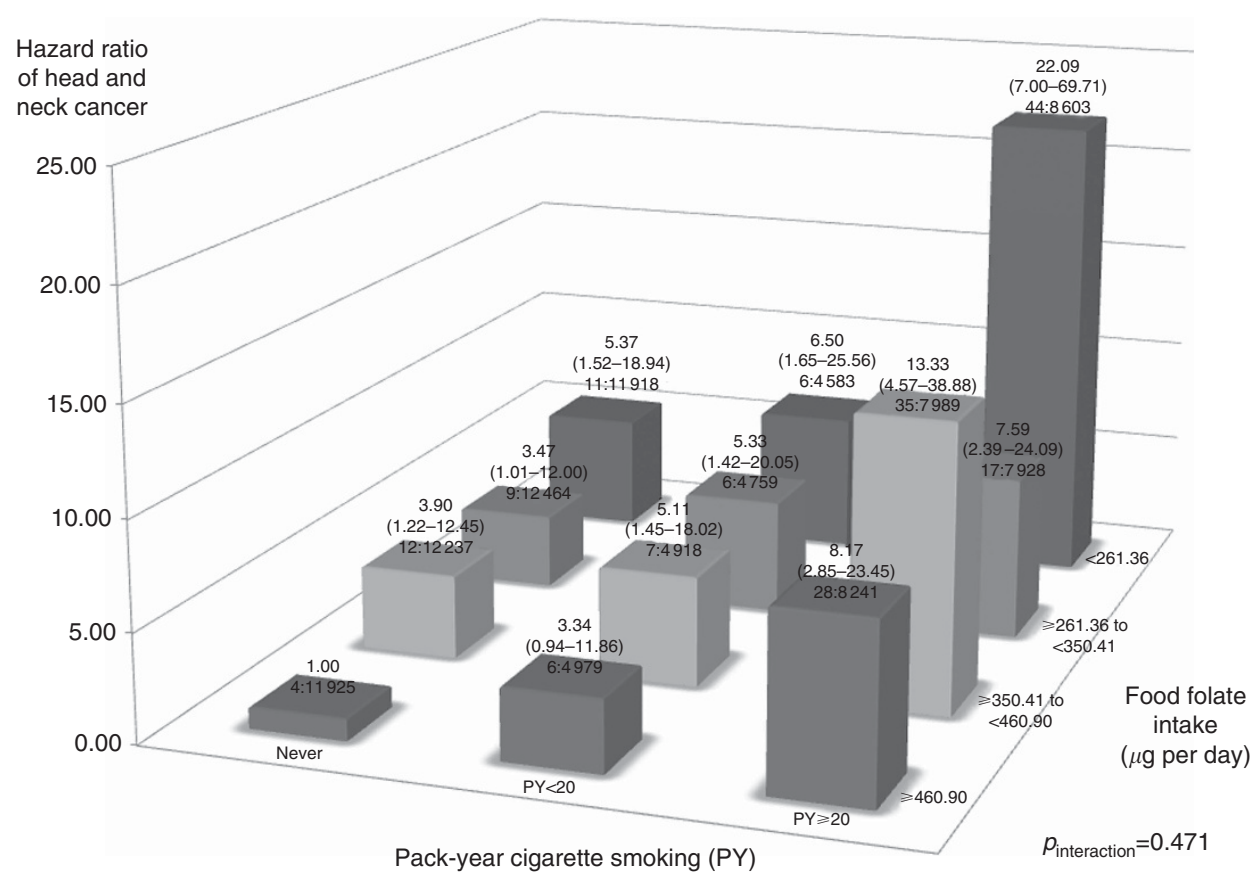

Figure 1. Hazard ratios (HRs) of head and neck cancer, and corresponding confidence intervals (95\% Cls), according to pack-year of cigarette smoking and food folate intake ( $\mu \mathrm{g}$ per day). The HRs were derived from Cox proportional hazard models, adjusting for age, sex, body mass index, education, race/ethnicity, pipe smoking status, cigar smoking status, pack-year cigarette smoking, alcohol drinking intensity, non-alcohol total energy, total vegetable and fruit intake. The number of cases and controls within each category was indicated below the corresponding HR as: 'number of cases: number of cohorts'. We found no interaction between smoking and food folate intake on HNC risk. 


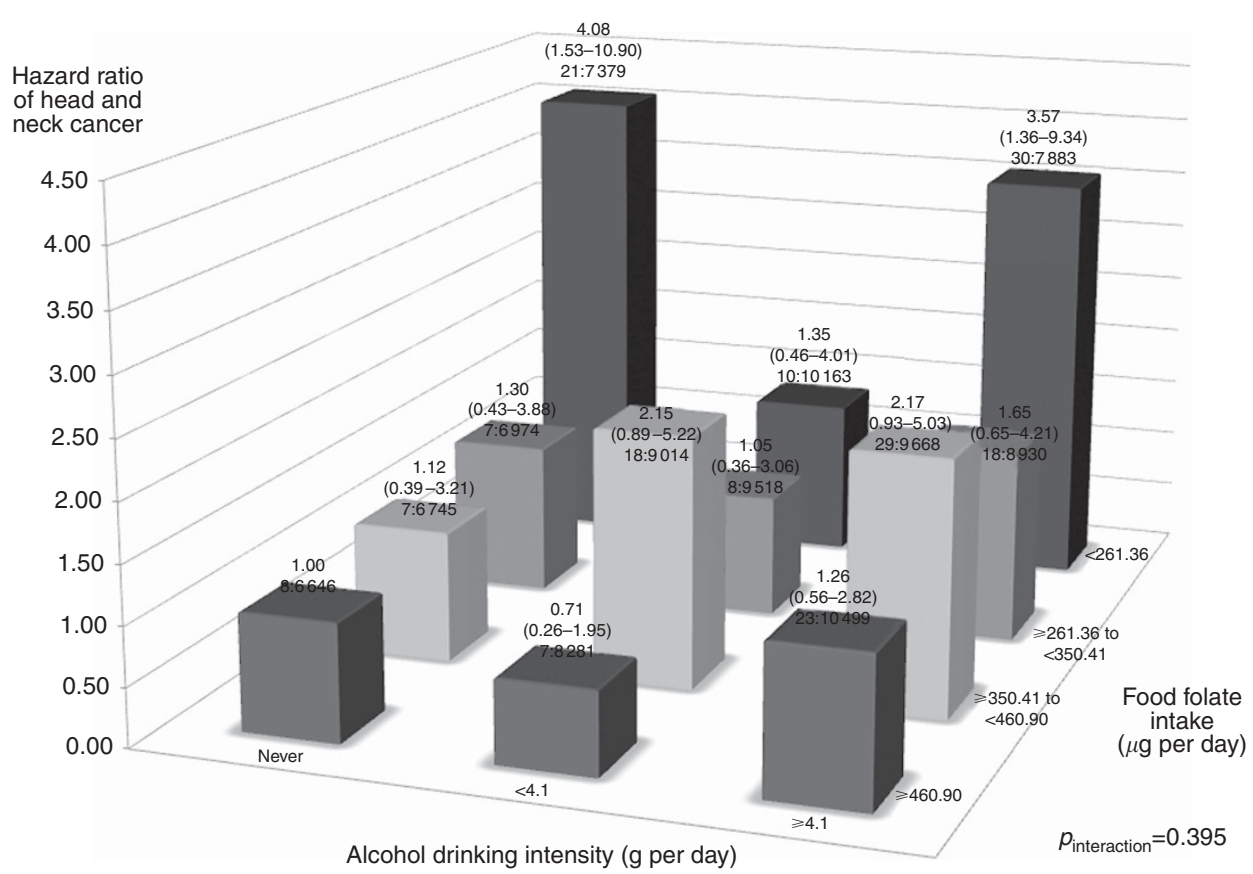

Figure 2. Hazard ratios (HRs) of head and neck cancer, and corresponding confidence intervals ( $95 \% \mathrm{Cls}$ ), according to alcohol drinking intensity (g per day) and food folate intake ( $\mu \mathrm{g}$ per day). The HRs were derived from Cox proportional hazard models, adjusting for age, sex, body mass index, education, race/ethnicity, pipe smoking status, cigar smoking status, pack-year cigarette smoking, alcohol drinking intensity, non-alcohol total energy, total vegetable and fruit intake. The number of cases and controls within each category was indicated below the corresponding $\mathrm{HR}$ as: 'number of cases: number of cohorts'. We found no interaction between drinking, and food folate intake on HNC risk.

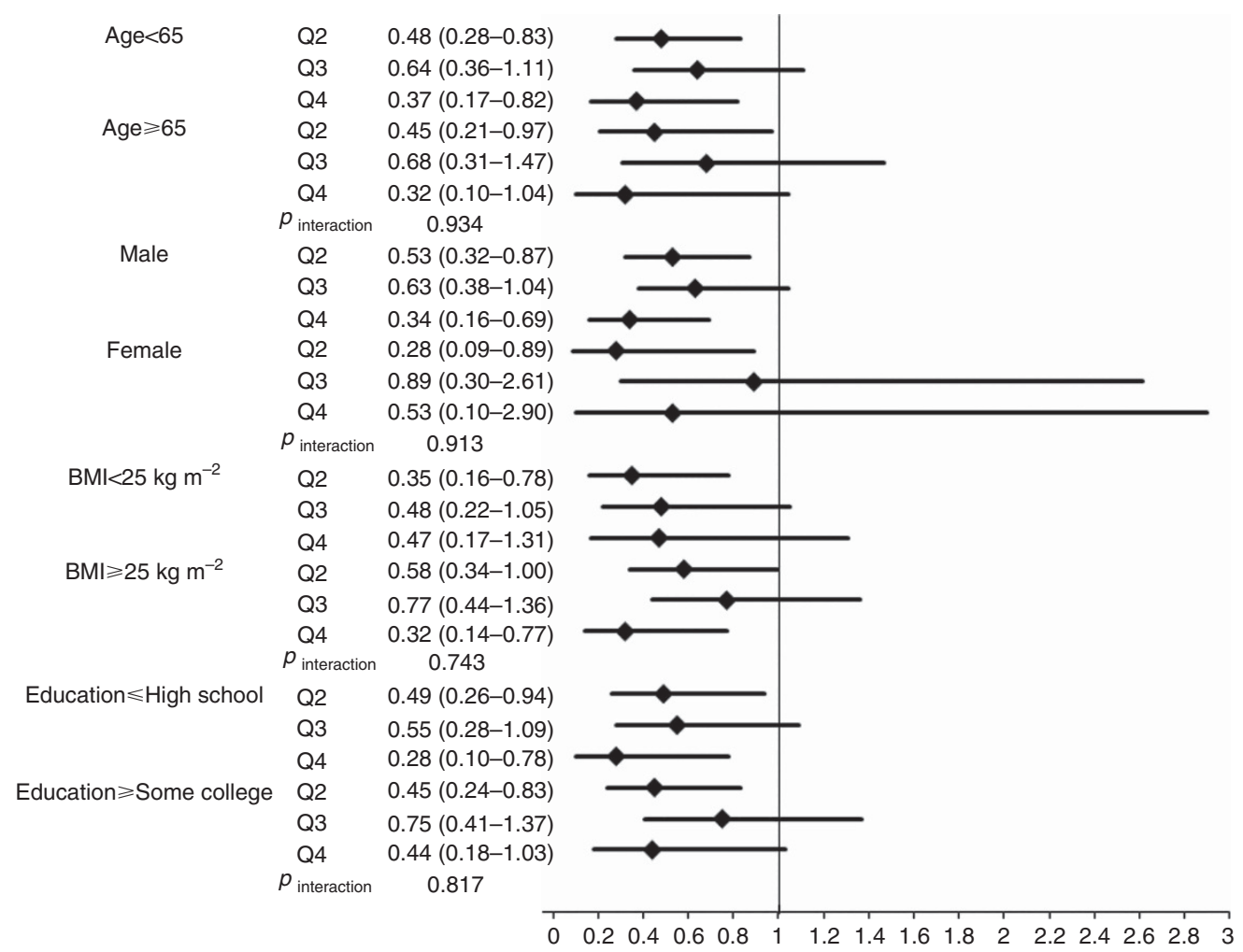

Figure 3. Impact of higher quartiles of food folate intake ( $\mathrm{Q} 2, \geqslant 261.36$ to $<350.41 \mu \mathrm{g}$ per day; $\mathrm{Q} 3$, $\geqslant 350.41$ to $<460.90 \mu \mathrm{g}$ per day; $\mathrm{Q} 4$, $\geqslant 460.90 \mu \mathrm{g}$ per day) on HNC risk compared to the lowest quartiles of food folate intake $(\mathrm{Q} 1,<261.36 \mu \mathrm{g}$ per day) according to selected covariates. The hazard ratios (HRs) were estimated from Cox proportional hazard models, adjusting for age, sex, body mass index, education, race/ ethnicity, pipe smoking status, cigar smoking status, pack-year cigarette smoking, alcohol drinking intensity, non-alcohol total energy, total vegetable and fruit intake. We found no interaction between selected covariates and total fibre intake on HNC risk. 
Thus, we can exclude the possibility of recall bias due to cancer outcome. We carefully adjusted for known confounders associated with HNC risk, including tobacco smoking, alcohol drinking and the intake of total fruit and vegetable. In addition, we were able to evaluate several types of dietary folate intake including fortified and supplemental folic acid.

Our sample size of HNC cases was limited; thus, statistical power was not so strong particularly for subsite analysis. However, this is the largest prospective cohort study to date. The time elapsed between exposure data collection and disease incidence may lead to some underestimate of the real association. We were unable to consider possible changes in diet between interview and diagnosis. We did not have information on relevant gene variants in one-carbon metabolism and HPV infection. Since these alleles are randomly assigned at the time of gamete formation, the distribution of alleles in our cohort is unlikely to confound the protective role of folate intake on HNC development (Smith and Ebrahim, 2003). In addition, since we would not expect HPV infection to be related specifically to folate intake, HPV infection status does not meet the properties of a confounder. In any case our data set included only 18 oropharyngeal cancers which was associated with HPV infection. When we divided HNC cases into subsites, we also considered the impact of folate intake on oropharyngeal cases only. We found a similar decreased trend on oropharyngeal cases.

In summary, our findings provided evidence of the protective role of dietary folate on HNC development.

\section{ACKNOWLEDGEMENTS}

We thank the NIH PLCO study group for allowing us to use the data. This work was supported by contracts from the Division of Cancer Prevention, National Cancer Institute, NIH, DHHS under Award Number N01-CN-25524 and by the National Center for Advancing Translational Sciences of the National Institutes of Health under Award Number UL1TR001067. In addition, this work was supported by JSPS Grant-in-Aid for Young Scientists (B) to D. Kawakita (No. 15K21283), and by Italian Foundation for Cancer Research (FIRC) to C. La Vecchia.

\section{CONFLICT OF INTEREST}

The authors declare no conflict of interest.

\section{REFERENCES}

Almadori G, Bussu F, Galli J, Cadoni G, Zappacosta B, Persichilli S, Minucci A, Giardina B (2002) Serum folate and homocysteine levels in head and neck squamous cell carcinoma. Cancer 94(4): 1006-1011.

Almadori G, Bussu F, Galli J, Cadoni G, Zappacosta B, Persichilli S, Minucci A, Giardina B, Maurizi M (2005) Serum levels of folate, homocysteine, and vitamin B12 in head and neck squamous cell carcinoma and in laryngeal leukoplakia. Cancer 103(2): 284-292.

Aune D, Deneo-Pellegrini H, Ronco AL, Boffetta P, Acosta G, Mendilaharsu M, De Stefani E (2011) Dietary folate intake and the risk of 11 types of cancer: a case-control study in Uruguay. Ann Oncol 22(2): 444-451.

Bailey LB (1990) Folate status assessment. J Nutr 120(Suppl 11): 1508-1511.

Barak AJ, Beckenhauer HC, Tuma DJ, Badakhsh S (1987) Effects of prolonged ethanol feeding on methionine metabolism in rat liver. Biochem Cell Biology = Biochim Biol Cell 65(3): 230-233.

Bidoli E, Bosetti C, La Vecchia C, Levi F, Parpinel M, Talamini R, Negri E, Maso LD, Franceschi S (2003) Micronutrients and laryngeal cancer risk in Italy and Switzerland: a case-control study. Cancer Causes Control 14(5): 477-484.
Bosetti C, Pelucchi C, La Vecchia C (2009) Diet and cancer in Mediterranean countries: carbohydrates and fats. Publ Health Nutr 12(9A): 1595-1600.

Choi SW, Mason JB (2002) Folate status: effects on pathways of colorectal carcinogenesis. J Nutr 132(8 Suppl): 2413S-2418S.

De Stefani E, Ronco A, Mendilaharsu M, Deneo-Pellegrini H (1999) Diet and risk of cancer of the upper aerodigestive tract - II. Nutrients. Oral Oncol 35(1): 22-26.

Duthie SJ (1999) Folic acid deficiency and cancer: mechanisms of DNA instability. Br Med Bull 55(3): 578-592.

Eleftheriadou A, Chalastras T, Ferekidou E, Yiotakis I, Kyriou L, Tzagarakis M, Ferekidis E, Kandiloros D (2006) Association between squamous cell carcinoma of the head and neck and serum folate and homocysteine. Anticancer Res 26(3B): 2345-2348.

Fanidi A, Relton C, Ueland PM, Midttun O, Vollset SE, Travis RC, Trichopoulou A, Lagiou P, Trichopoulos D, Bueno-de-Mesquita HB, Ros M, Boeing H, Tumino R, Panico S, Palli D, Sieri S, Vineis P, Sanchez MJ, Huerta JM, Barricarte Gurrea A, Lujan-Barroso L, Quiros JR, Tjonneland A, Halkjaer J, Boutron-Ruault MC, Clavel-Chapelon F, Cadeau C, Weiderpass E, Johansson M, Riboli E, Brennan P, Johansson M (2015) A prospective study of one-carbon metabolism biomarkers and cancer of the head and neck and esophagus. Int J Cancer 136(4): 915-927.

Freedman ND, Park Y, Subar AF, Hollenbeck AR, Leitzmann MF, Schatzkin A, Abnet CC (2008) Fruit and vegetable intake and head and neck cancer risk in a large United States prospective cohort study. Int J Cancer 122(10): 2330-2336.

Galeone C, Edefonti V, Parpinel M, Leoncini E, Matsuo K, Talamini R, Olshan AF, Zevallos JP, Winn DM, Jayaprakash V, Moysich K, Zhang ZF, Morgenstern H, Levi F, Bosetti C, Kelsey K, McClean M, Schantz S, Yu GP, Boffetta P, Lee YC, Hashibe M, La Vecchia C, Boccia S (2015) Folate intake and the risk of oral cavity and pharyngeal cancer: a pooled analysis within the International Head and Neck Cancer Epidemiology Consortium. Int J Cancer 136(4): 904-914.

Gorgulu O, Selcuk T, Ozdemir S, Sayar C, Beyazit Y, Akbas Y (2010) Evaluation of the roles of serum vitamin $\mathrm{B}(12)$, folate and homocysteine levels in laryngeal squamous cell carcinoma. J Int Med Res 38(6): 2047-2052.

Hasegawa M, Nelson HH, Peters E, Ringstrom E, Posner M, Kelsey KT (2002) Patterns of gene promoter methylation in squamous cell cancer of the head and neck. Oncogene 21(27): 4231-4236.

Hashibe M, Brennan P, Chuang SC, Boccia S, Castellsague X, Chen C, Curado MP, Dal Maso L, Daudt AW, Fabianova E, Fernandez L, Wunsch-Filho V, Franceschi S, Hayes RB, Herrero R, Kelsey K, Koifman S, La Vecchia C, Lazarus P, Levi F, Lence JJ, Mates D, Matos E, Menezes A, McClean MD, Muscat J, Eluf-Neto J, Olshan AF, Purdue M, Rudnai P, Schwartz SM, Smith E, Sturgis EM, Szeszenia-Dabrowska N, Talamini R, Wei Q, Winn DM, Shangina O, Pilarska A, Zhang ZF, Ferro G, Berthiller J, Boffetta P (2009) Interaction between tobacco and alcohol use and the risk of head and neck cancer: pooled analysis in the International Head and Neck Cancer Epidemiology Consortium. Cancer Epidemiol Biomarkers Prev 18(2): 541-550.

Heimburger DC (1992) Localized deficiencies of folic acid in aerodigestive tissues. Ann NY Acad Sci 669: 87-95. discussion 95-96.

Kim YI (1999) Folate and carcinogenesis: evidence, mechanisms, and implications. J Nutr Biochem 10(2): 66-88.

Lamprecht SA, Lipkin M (2003) Chemoprevention of colon cancer by calcium, vitamin D and folate: molecular mechanisms. Nat Rev Cancer 3(8): 601-614.

Lubin JH, Purdue M, Kelsey K, Zhang ZF, Winn D, Wei Q, Talamini R, Szeszenia-Dabrowska N, Sturgis EM, Smith E, Shangina O, Schwartz SM, Rudnai P, Neto JE, Muscat J, Morgenstern H, Menezes A, Matos E, Mates IN, Lissowska J, Levi F, Lazarus P, La Vecchia C, Koifman S, Herrero R, Franceschi S, Wunsch-Filho V, Fernandez L, Fabianova E, Daudt AW, Maso LD, Curado MP, Chen C, Castellsague X, Brennan P, Boffetta P, Hashibe M, Hayes RB (2009) Total exposure and exposure rate effects for alcohol and smoking and risk of head and neck cancer: a pooled analysis of case-control studies. Am J Epidemiol 170(8): 937-947.

Lucenteforte E, Garavello W, Bosetti C, La Vecchia C (2009) Dietary factors and oral and pharyngeal cancer risk. Oral Oncol 45(6): 461-467.

Marur S, D'Souza G, Westra WH, Forastiere AA (2010) HPV-associated head and neck cancer: a virus-related cancer epidemic. Lancet Oncol 11(8): 781-789.

Mason JB, Choi SW (2005) Effects of alcohol on folate metabolism: implications for carcinogenesis. Alcohol 35(3): 235-241. 
Matsuo K, Rossi M, Negri E, Oze I, Hosono S, Ito H, Watanabe M, Yatabe Y, Hasegawa Y, Tanaka H, Tajima K, La Vecchia C (2012) Folate, alcohol, and aldehyde dehydrogenase 2 polymorphism and the risk of oral and pharyngeal cancer in Japanese. Eur J Cancer Prev 21(2): 193-198.

McLaughlin JK, Gridley G, Block G, Winn DM, Preston-Martin S, Schoenberg JB, Greenberg RS, Stemhagen A, Austin DF, Ershow AG et al. (1988) Dietary factors in oral and pharyngeal cancer. J Natl Cancer Inst 80(15): 1237-1243.

National Cancer Institute (2017) Diet history questionnaire. Risk factor monitoring and methods. Version current 30 Nov 2016. Internet http:// www.riskfactor.cancer.gov/DHQ (accessed 30 November 2016).

Negri E, Franceschi S, Bosetti C, Levi F, Conti E, Parpinel M, La Vecchia C (2000) Selected micronutrients and oral and pharyngeal cancer. Int J Cancer 86(1): 122-127.

Oaks BM, Dodd KW, Meinhold CL, Jiao L, Church TR, Stolzenberg-Solomon RZ (2010) Folate intake, post-folic acid grain fortification, and pancreatic cancer risk in the prostate, lung, colorectal, and ovarian cancer screening trial. Am J Clin Nutr 91(2): 449-455.

Pavia M, Pileggi C, Nobile CG, Angelillo IF (2006) Association between fruit and vegetable consumption and oral cancer: a meta-analysis of observational studies. Am J Clin Nutr 83(5): 1126-1134.

Pelucchi C, Talamini R, Negri E, Levi F, Conti E, Franceschi S, La Vecchia C (2003) Folate intake and risk of oral and pharyngeal cancer. Ann Oncol 14(11): 1677-1681.

Piyathilake CJ, Hine RJ, Dasanayake AP, Richards EW, Freeberg LE, Vaughn WH, Krumdieck CL (1992) Effect of smoking on folate levels in buccal mucosal cells. Int J Cancer 52(4): 566-569.

Prorok PC, Andriole GL, Bresalier RS, Buys SS, Chia D, Crawford ED, Fogel R, Gelmann EP, Gilbert F, Hasson MA, Hayes RB, Johnson CC, Mandel JS, Oberman A, O'Brien B, Oken MM, Rafla S, Reding D, Rutt W, Weissfeld JL, Yokochi L, Gohagan JK, Prostate LC. Ovarian Cancer Screening Trial Project T (2000) Design of the Prostate, Lung, Colorectal and Ovarian (PLCO) Cancer Screening Trial. Controlled Clinical Trials 21(6 Suppl): 273S-309S.

Raval GN, Sainger RN, Rawal RM, Patel JB, Patel BP, Jha FP, Patel DD, Patel PS (2002) Vitamin B(12) and folate status in head and neck cancer. Asian Pacific J Cancer Prev 3(2): 155-162.

Shanmugham JR, Zavras AI, Rosner BA, Giovannucci EL (2010) Alcoholfolate interactions in the risk of oral cancer in women: a prospective cohort study. Cancer Epidemiol Biomarkers Prev 19(10): 2516-2524.

Siegel RL, Miller KD, Jemal A (2016) Cancer statistics, 2016. CA: Cancer J Clin 66(1): 7-30
Smith GD, Ebrahim S (2003) 'Mendelian randomization': can genetic epidemiology contribute to understanding environmental determinants of disease? Int J Epidemiol 32(1): 1-22.

Smith IM, Mydlarz WK, Mithani SK, Califano JA (2007) DNA global hypomethylation in squamous cell head and neck cancer associated with smoking, alcohol consumption and stage. Int J Cancer 121(8): 1724-1728.

Subar AF, Midthune D, Kulldorff M, Brown CC, Thompson FE, Kipnis V, Schatzkin A (2000) Evaluation of alternative approaches to assign nutrient values to food groups in food frequency questionnaires. Am J Epidemiol 152(3): $279-286$

Subar AF, Thompson FE, Smith AF, Jobe JB, Ziegler RG, Potischman N, Schatzkin A, Hartman A, Swanson C, Kruse L et al. (1995) Improving food frequency questionnaires: a qualitative approach using cognitive interviewing. J Am Dietetic Assoc 95: 781-788. quiz 789-790.

Suzuki T, Matsuo K, Hasegawa Y, Hiraki A, Wakai K, Hirose K, Saito T, Sato S, Ueda R, Tajima K (2007) One-carbon metabolism-related gene polymorphisms and risk of head and neck squamous cell carcinoma: casecontrol study. Cancer Sci 98(9): 1439-1446.

Tavani A, Malerba S, Pelucchi C, Dal Maso L, Zucchetto A, Serraino D, Levi F, Montella M, Franceschi S, Zambon A, La Vecchia C (2012) Dietary folates and cancer risk in a network of case-control studies. Ann Oncol 23(10): 2737-2742.

Ulrich CM, Grady WM (2010) Linking epidemiology to epigenomics - where are we today? Cancer Prev Res 3(12): 1505-1508.

University of Minnesota Nutrition Co-ordinating Center. NDSR descriptive overview. Version current 30 November 2016. Internet http:// www.ncc.umn.edu/ (accessed 30 November 2016).

Vollset SE, Clarke R, Lewington S, Ebbing M, Halsey J, Lonn E, Armitage J, Manson JE, Hankey GJ, Spence JD, Galan P, Bonaa KH, Jamison R, Gaziano JM, Guarino P, Baron JA, Logan RF, Giovannucci EL, den Heijer M, Ueland PM, Bennett D, Collins R, Peto R. Collaboration BVTT (2013) Effects of folic acid supplementation on overall and site-specific cancer incidence during the randomised trials: meta-analyses of data on 50,000 individuals. Lancet 381(9871): 1029-1036.

Weinstein SJ, Gridley G, Harty LC, Diehl SR, Brown LM, Winn DM, Bravo-Otero E, Hayes RB (2002) Folate intake, serum homocysteine and methylenetetrahydrofolate reductase (MTHFR) C677T genotype are not associated with oral cancer risk in Puerto Rico. J Nutr 132(4): 762-767.

This work is published under the standard license to publish agreement. After 12 months the work will become freely available and the license terms will switch to a Creative Commons AttributionNonCommercial-Share Alike 4.0 Unported License. 